\title{
Kinetics of scandium recovery by TVEX-TBP from the solution formed after the salt chlorinator cake leaching
}

\author{
Vadym Korovin ${ }^{1, *}$, Yurii Pohorielov ${ }^{1}$, Yurii Shestak ${ }^{1}$, Oleksandr Valiaiev ${ }^{1}$, and Jose Luis \\ Cortina $^{2}$ \\ ${ }^{1}$ Institute of Geotechnical Mechanics named by N. Poljakov of National Academy of Sciences of \\ Ukraine, 49005, Dnipro, Simferopolska Str., 2a, Ukraine \\ ${ }^{2}$ Chemical Engineering Department and Barcelona Research Center for Multiscale Science and \\ Engineering, UPC-BarcelonaTECH, B-08019, Barcelona, d'Eduard Maristany Ave., 10-14, Spain
}

\begin{abstract}
Kinetics of scandium recovery by TVEX containing tributyl phosphate was studied from the clarified leaching solution of salt chlorinator cake. To assess the contribution of each diffusion phase, experimental data were analyzed using a graphic method. To define the contribution of chemical interaction into the scandium extraction process, recovery kinetics was quantitatively described using pseudo-first order, pseudo-second order kinetic models and Elovich equation in linearized form. It was established that recovery kinetics was most accurately described with the pseudo-second-order model.
\end{abstract}

\section{Introduction}

Impregnated resins and Levextrel-type materials known as "Solid Extractants" (TVEX) in countries of the Commonwealth of Independent States, which combine properties of ionexchange resins and solvent extractants, are increasingly used for scandium recovery in addition to solvent extraction and sorption [1]. Authors of $[2,3]$ measured equilibrium and kinetic parameters of scandium extraction by impregnated resins based on hypercrosslinked polystyrene and contained di-(2-ethylhexyl) phosphoric acid (D2EHPA) and different-radical phosphine oxide (FOR) from acidic sulphate-chloride and nitric solutions. Scandium extraction was studied [4] from a $6 \mathrm{~mol} / \mathrm{dm}^{3}$ sulphuric solution by TVEX contained tributyl phosphate (TBP), D2EHPA, dibenzo-18-crown-6 (DB18C6), 18-crown-6 (18C6) as well as TBP/DB18C6 and D2EHPA/DB18C6.

A set of fundamental and applied researches we performed earlier showed [5-12] that TVEX containing organophosphorus extractants are the most expedient and promising materials for scandium selective recovery from ores and industrial waste. In cooperation with Titanium Institute and Ust-Kamenogorsk Titanium Magnesium Plant (TMK), we have worked out and implemented the technology of scandium selective recovery using TVEX contained tributyl phosphate (TVEX-TBP) from hydrochloric pulps formed after leaching

\footnotetext{
*Corresponding author: sorbent2005@ukr.net
} 
salt chlorinator cake. This technology was named TVEX-Sc-Process [9, 10] and tested later at Zaporizhzhia Titanium and Magnesium Combine.

The work described in the paper was aimed to measure kinetic parameters of scandium extraction by TVEX-TBP from the clarified solution after leaching salt chlorinator cake produced at Zaporizhzhia Titanium and Magnesium Combine State Enterprise (ZTMC SE). The need to perform the study is associated with the change of the initial raw materials, reagents and process parameters of titanium chloride production that required to specify scandium recovery parameters.

\section{Methods}

\subsection{Materials and reagents}

The research was carried out using TVEX-50\% TBP manufactured at Smoly State Enterprise (Specification TU U 20.1-30168850-051:2012) by suspension co-polymerization of styrene and divinylbenzene in extractant presence. TVEX-TBP are spheric beads of macroporous copolymer contained $50 \%$ of tributyl phosphate and $25 \%$ of divinylbenzene. The material features the following properties: phosphorus weight fraction - at least $5.3 \%$; grain size range in air-dry condition is $(0.63$ to 2.5$) \mathrm{mm}$, weight ratio of effective size fraction is $96 \%$, mechanical strength is $96 \%$, bulk density is $0.58 \mathrm{~g} / \mathrm{cm}^{3}$, operating temperature range is $(20 \text { to } 80)^{\circ} \mathrm{C}$.

To measure kinetic parameters of TVEX-TBP, effective size fraction $\mathrm{d}=(1.0$ to 1.25$) \mathrm{mm}$ was screened using MLW Thyr 2 vibrating sieve.

Fresh ZTMC cake of a salt chlorinator was used during experiments.

All reagents used in experiments were at least reagent grade.

\subsection{Experimental technique}

To study scandium extraction, salt chlorinator cake was crushed to coarseness $\leq 10 \mathrm{~mm}$ and leached with hydrochloric acid solution with concentration $20 \mathrm{~g} / \mathrm{dm}^{3}$ at phase ratio Solid:Liquid $=1: 1.2$ and room temperature to its complete dissolution and further filtration in a Buchner funnel under vacuum through White Ribbon filter. The prepared clarified solution had density $1.305 \mathrm{~g} / \mathrm{dm}^{3}$.

Extraction kinetics was studied by the limited solution volume method at phase ratio Solid:Liquid = 1:50 (TVEX-TBP weighed sample was $2 \mathrm{~g}$ ) during 24 hours at a temperature of $20 \pm 2{ }^{\circ} \mathrm{C}$ from the clarified solution with scandium concentration $53 \mathrm{mg} / \mathrm{dm}^{3}$. The study was carried out in a temperature-controlled cell with agitation by a MLW ER 10 propeller-type agitator provided rotation speed more than $200 \mathrm{rpm}$. Temperature was controlled using MLW UH8 ultra thermostat.

\subsection{Analytical techniques}

The density of clarified solution produced from the salt chlorinator cake was measured using a picnometer.

Scandium concentration in clarified solution was measured using Labtam 8440 atomic emission spectrometer.

TVEX-TBP capacity was calculated by the difference of scandium concentration in the aqueous phase by the following equation: 


$$
q_{\tau}=\frac{\left([S c]_{0}-[S c]_{\tau}\right) \cdot V}{m}
$$

where $[S c]_{0}$ and $[S c]_{\tau}$ are initial scandium concentration and its concentration in time point $\tau$, min, in the aqueous phase, respectively, $\mathrm{mg} / \mathrm{dm}^{3}, V$ is the solution volume, $\mathrm{dm}^{3}$, and $m$ is the mass of the air dry resin, g.

\section{Results and discussion}

Figure 1 shows an integral kinetic curve of scandium extraction by TVEX-TBP from scandium clarified solution with initial concentration $53 \mathrm{mg} / \mathrm{dm}^{3}$.

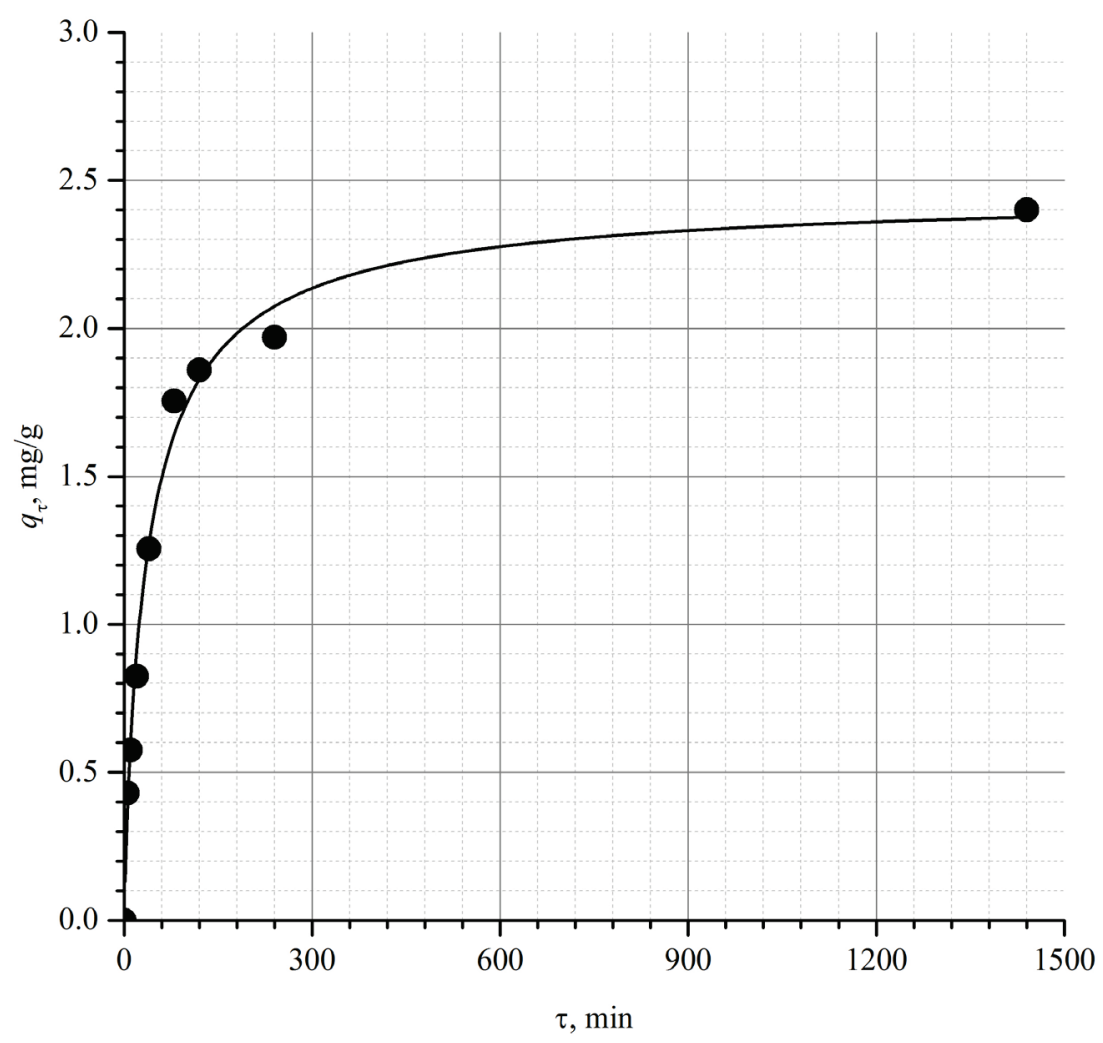

Fig. 1. Integral kinetic plot of scandium extraction by TVEX-TBP: $(\bullet)$ experimental data, (-) pseudosecond order fit.

As it is seen from the data obtained, TVEX-TBP featured high kinetic characteristics; thus, about $80 \%$ of scandium were recovered during 1.5 hours. These results agreed with the data previously obtained for scandium extraction from $8 \mathrm{~mol} / \mathrm{dm}^{3}$ model hydrochloric solution [5]. TVEX-TBP high kinetic parameters were due to its meso- and macroporous structure, which had the following parameters [10] according to the mercury porosimetry data: total pore volume $1.39 \mathrm{~cm}^{3} / \mathrm{g}$, specific surface area $163.42 \mathrm{~m} / \mathrm{g}$, and average effective pore radius $16.95 \mathrm{~nm}$. We showed previously [9, 11] that this type of materials had a globular structure, where each individual bead consisted of a large number of microglobules formed during the extractant separation into a separate phase. Microglobule dimensions and the space between them depended upon the extractant type and amount as 
well as cross-linking degree. Almost the entire surface and pore volume in TVEX-TBP had multi-fractal properties.

Since impregnated resins and TVEX-TBP combine the properties of sorbents and selective solvent extractants, extraction kinetics for these materials [1] was characterized with the approaches used for ion-exchange resins [13]. Extraction process consists of several phases: metal ion diffusion through a liquid film adjacent to the TVEX-TBP bead surface (film diffusion), diffusion inside the bead in aqueous solution (intra-particle diffusion), the chemical reaction of the extracted component with the extractant and diffusion of reaction products inside the bead in extractant. The reaction with recovered component describes chemical kinetics while the rest phases are of diffusion nature and described by Fick's laws. In most cases, the recovery process is limited by the film or intraparticle diffusion phases.

To assess the contribution of each diffusion phase, experimental data were analyzed using a graphic method in coordinate systems $F-\tau^{1 / 2}$, and $B \tau-\tau$ (Fig. 2, 3), where: $\tau$ is time, $F$ is the fractional equilibrium attaining function, $B \tau$ is dimensionless time proposed by Boyd and tabulated as the $B \tau=f(F)$ dependence [13]. Linearity of plots in corresponding coordinate systems allowed to determine the recovery limiting phase. Determination factor $R^{2}$ served a linearity criterion.

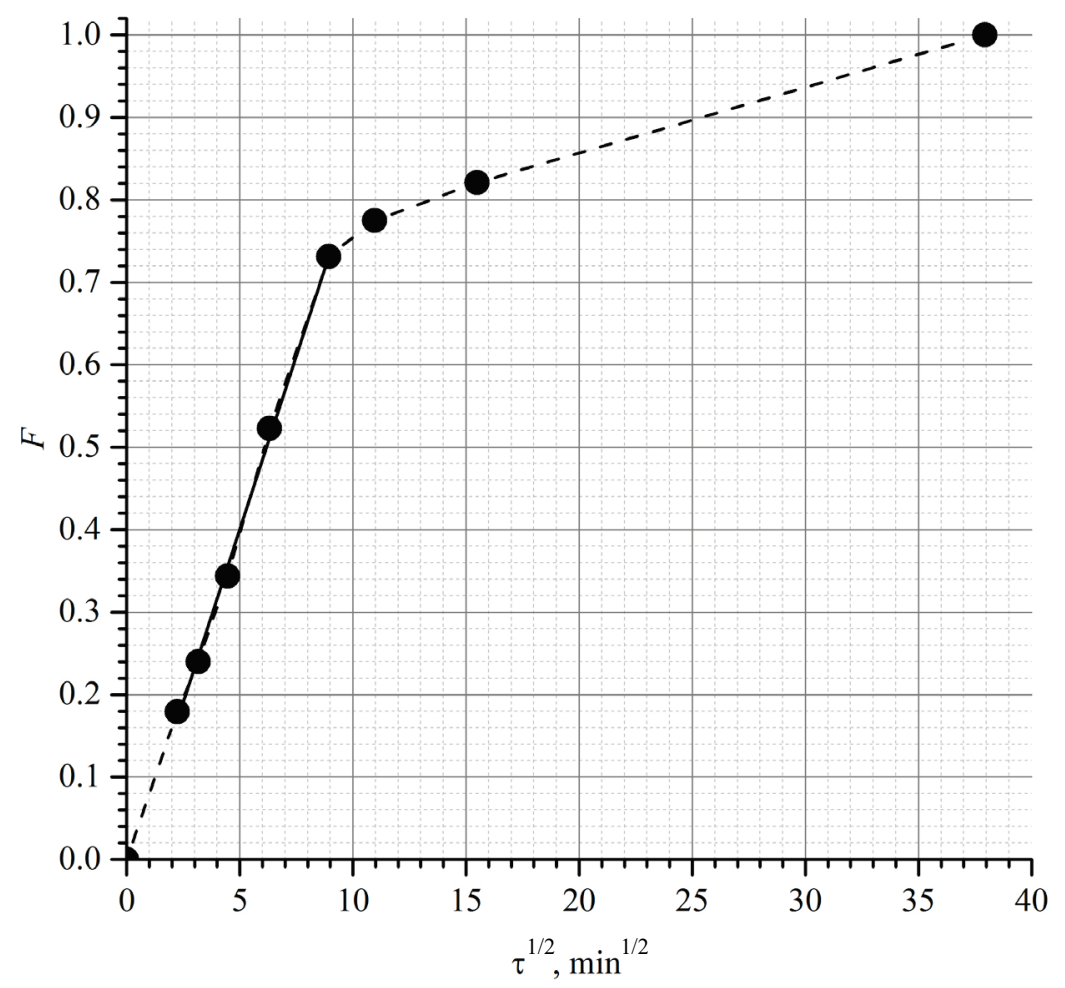

Fig. 2. Kinetic modelling of scandium recovery in coordinates $F=f\left(\tau^{1 / 2}\right)$.

Kinetic plot of scandium recovery in coordinates $F=f\left(\tau^{1 / 2}\right)$ (Fig. 2) was a straight line extended almost from the coordinate origin up to the equilibrium attaining degree 0.74 $\left(R^{2}=0.9981\right)$ that indicated intra-particle diffusion as a limiting phase. Then, deviation from the linear dependence was observed indicating significant contribution of film diffusion.

Linear dependence $B \tau=f(\tau)\left(R^{2}=0.9770\right)$ was also typical for intra-particle diffusion (Fig. 3), where relative rate [13] of scandium recovery was also directly proportional to 
diffusion factor and inversely proportional to the square of the TVEX-TBP bead radius; and effective diffusion factor could be calculated as:

$$
D=\frac{B \tau \cdot r^{2}}{\pi^{2} \cdot \tau},
$$

where $D$ is effective internal diffusion factor, $\mathrm{m}^{2} / \mathrm{s} ; r$ is average bead radius, $\mathrm{m}$, calculated by the formula [5]:

$$
r=0.435 \cdot\left(r_{\min }+r_{\max }\right),
$$

where $r_{\min }$ and $r_{\max }$ are minimum and maximum bead radius, correspondingly, $\mathrm{m}$.

Effective diffusion factor was $D=3.64 \cdot 10^{-12} \mathrm{~m}^{2} / \mathrm{s}$ that agreed with the previously calculated diffusion factor $D=3.6 \cdot 10^{-12} \mathrm{~m}^{2} / \mathrm{s}$ for scandium extraction by TVEX-TBP from the model $8 \mathrm{~mol} / \mathrm{dm}^{3}$ hydrochloric solution [5].

Half-recovery time, s, calculated by the formula:

$$
\tau_{1 / 2}=0.03 \cdot r^{2} / D
$$

is about 32.9 minutes and close to experimental data ( $\tau_{1 / 2}$ about 40 minutes).

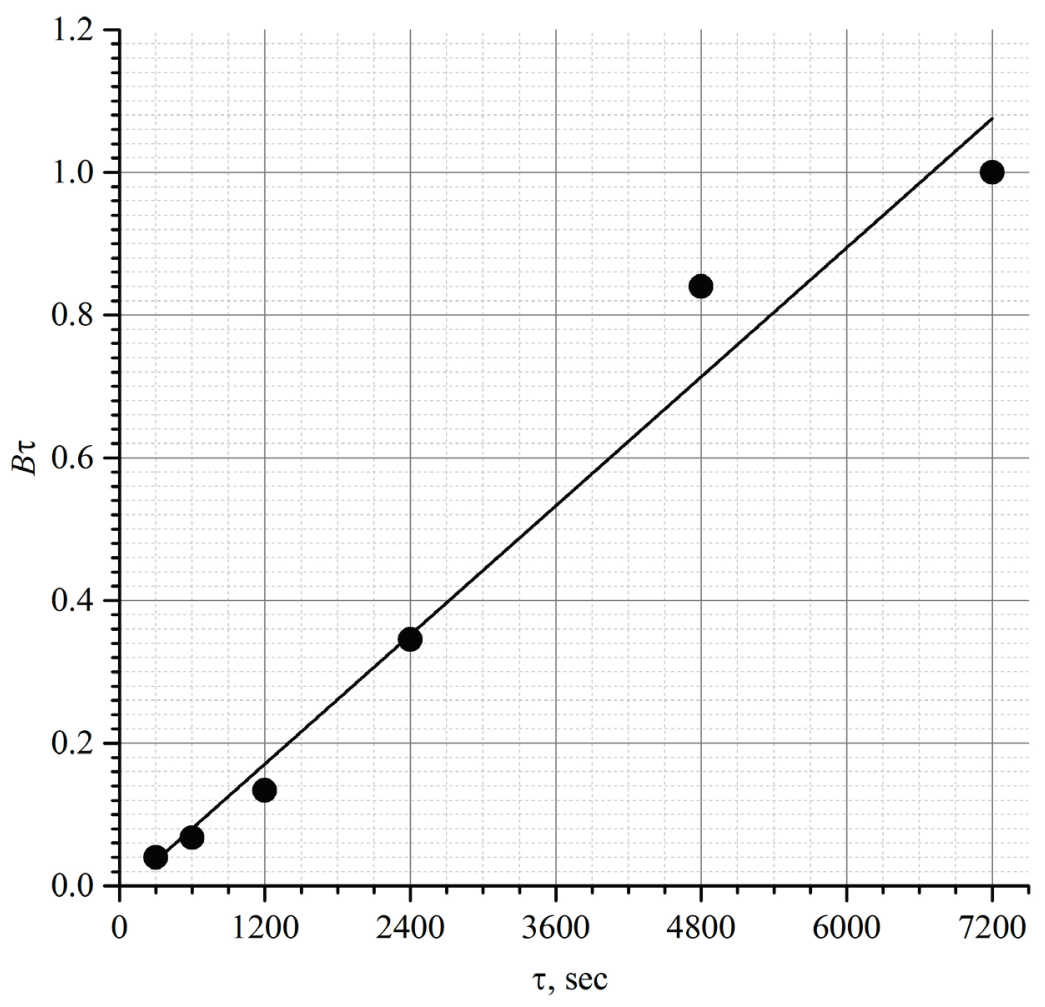

Fig. 3. Kinetic modelling of scandium recovery in coordinates $B \tau=f(\tau)$.

To define the contribution of chemical interaction into the scandium extraction process, recovery kinetics was quantitatively described using pseudo-first order, pseudo-second order kinetic models and Elovich equation in linearized form; their parameters are given in Table 1. Initial recovery rate $h$ for the pseudo-second model, $\mathrm{mg} /(\mathrm{g} \cdot \mathrm{min})$, was calculated by the equation: 


$$
h=k_{2} \cdot q_{e}^{2} .
$$

The pseudo-second-order model fitted most precisely $\left(R^{2}=0.9996\right)$ experimental data. Rate constant $k_{2}$ for the pseudo-second order model was $1.095 \cdot 10^{-2} \mathrm{~g} /(\mathrm{mg} \cdot \mathrm{min})$.

Calculated equilibrium capacity $q_{e}$ and experimental capacity $q_{\exp }$ had similar values $2.456 \mathrm{mg} / \mathrm{g}$ and $2.40 \mathrm{mg} / \mathrm{g}$, correspondingly.

Table 1. Kinetic data processing results.

\begin{tabular}{|c|c|c|}
\hline Model equation & Parameters & Value \\
\hline \multirow{3}{*}{$\begin{array}{c}\text { Pseudo-first-order } \\
q_{\tau}=q_{e}\left(1-\exp \left(-k_{1} \cdot \tau\right)\right)\end{array}$} & Calculated equilibrium capacity $q_{e}, \mathrm{mg} / \mathrm{g}$ & 1.630 \\
\hline & Rate constant $k_{1}, \min ^{-1}$ & $6.702 \cdot 10^{-3}$ \\
\hline & Determination factor $R^{2}$ & 0.8204 \\
\hline \multirow{4}{*}{$\begin{array}{l}\text { Pseudo-second-order } \\
\qquad q_{\tau}=\frac{\tau \cdot k_{2} \cdot q_{e}^{3}}{q_{e}+\tau \cdot k_{2} \cdot q_{e}^{2}}\end{array}$} & Calculated equilibrium capacity $q_{e}, \mathrm{mg} / \mathrm{g}$ & 2.456 \\
\hline & Rate constant $k_{2}, \mathrm{~g} /(\mathrm{mg} \cdot \mathrm{min})$ & $1.095 \cdot 10^{-2}$ \\
\hline & Determination factor $R^{2}$ & 0.9996 \\
\hline & Initial sorption rate $h, \mathrm{mg} /(\mathrm{g} \cdot \mathrm{min})$ & 3.976 \\
\hline \multirow{3}{*}{$\begin{array}{c}\text { Elovich } \\
q_{\tau}=\frac{1}{\beta} \ln (\alpha \beta)+\frac{1}{\beta} \ln (\tau)\end{array}$} & Initial sorption rate $\alpha, \mathrm{mg} /(\mathrm{g} \cdot \mathrm{min})$ & 0.242 \\
\hline & Desorption constant $\beta, \mathrm{g} / \mathrm{mg}$ & 2.603 \\
\hline & Determination factor $R^{2}$ & 0.9478 \\
\hline \multicolumn{2}{|c|}{ Experimental equilibrium capacity $q_{\text {exp }}, \mathrm{mg} / \mathrm{g}$} & 2.40 \\
\hline
\end{tabular}

The pseudo-second-order model adequately fitted kinetics of scandium recovery by FOR-impregnated resin from nitric solutions [3] and by Lewatit TP 272 contained Cyanex 272 from sulphuric ones [1].

\section{Conclusions}

As a result of the study, it was established that TVEX-TBP had high kinetic properties during scandium recovery from the clarified solution produced by leaching the salt chlorinator cake.

Sorption kinetics was most accurately described with the pseudo-second-order model. Experimental data were evaluated in coordinate systems $F-\tau^{1 / 2}$ and $B \tau-\tau$. Scandium effective diffusion factor in TVEX-TBP was calculated. It was shown that its value correlated to the diffusion factor value when extracting scandium by TVEX-TBP from the model hydrochloric solution.

The results obtained may be used when creating the complex processing and disposal technology of salt chlorinator cake formed as a waste at Zaporizhzhia Titanium and Magnesium Combine State Enterprise.

\section{References}

1. Bao Shenxu, W. Hawker, J. Vaughan, Solv. Extr. and Ion Exch 36, 100-113 (2018)

2. Pyae Phyo Aung, Troshkina, I.D., Veselova, O.A., Davidovich, Yu.A., Tsyurupa, M.P., Davankov, V.A. (2017). Sorption of scandium by hypercrosslinked polystyrene impregnate containing organophosphorus acids. Sorbtsionnye i khromatograficheskiye processy [Sorption and Chromatographic Processes], 17, 45-53

3. Pyae Phyo Aung, Veselova, O.A., Troshkina, I.D. (2017). Kinetics of scandium sorption by impregnate containing phosphinoxide. Izv. Vyssh. Uchebn. Zaved. Khim. I 
Khim. Tekhnol. [Khim. I Khim. Tekhnol. Rus. Jour. of Chem. and Chem. Tech.], 60, 28-30

4. Shirokova, A.G., Pasechnik, L.A., Yatsenko, S.P. (2014). Prospects of application of microencapsulated extractants for extraction of scandium and rare-earth elements. Tsvetnye Metaly [Non-Ferrous Metals Journal], 3, 44-48

5. Korovin, V., Shestak, Yu., Pohorielov, Yu. (2008). Sorption materials for scandium extraction from acid medium. Voprosy khimii $i$ khimicheskoi tekhnologii [Issues of Chemistry and Chemical Technology], 2, 156-159

6. V. Korovin, Yu. Shestak, Yu. Pohorielov, Scandium: Compounds, Productions and Applications. Nova Science Publishers Inc, 77-100 (2011)

7. V. Korovin, Yu. Shestak, Yu. Pogorelov, Hydrometallurgy 52, 1-8 (1999)

8. V. Korovin, Yu. Shestak, Hydrometallurgy 95, 346-349 (2009)

9. V. Korovin, Yu. Shestak, Yu. Pogorelov, J.-L. Cortina, Solvent Extraction and Liquid Membranes: Fundamentals and Applications in New Materials. CRC Press, Taylor \& Francis Group, 261-301 (2008)

10. Korovin, V.Yu., Shestak, Yu.G., Valyaev, A.M. (2014). Porous characteristics and fractal properties of TVEX-TBP matrix, Voprosy khimii i khimicheskoi tekhnologii [Issues of Chemistry and Chemical Technology], 4(97), 51-58

11. Korovin, V., Shestak, Yu., Pohorielov, Yu. (2015). Study and practical application of hydrometallurgical methods for scandium extraction during complex ore processing, Geotekhnicheskaya Mekhanica [Geotechnical Mechanics], 121, 214-226

12. Poturaev, V.N., Voloshin, A.I., Ponomarev, B.V. (1989). One-dimensional flow of a two-phase medium, Soviet Applied Mechanics, 25(8), 843-850

13. Zakharov, E.I., Riabchikov, B.E., Diakov, S.V. (1987). Ionoobmennoye oborudovanie atomnoy promyshlennosti. Moskva: Energoatomizdat 